Marquette University

e-Publications@Marquette

Mechanical Engineering Faculty Research and

Publications

Mechanical Engineering, Department of

4-6-2010

\title{
Multidisciplinary Engineering Systems 2nd and 3rd Year College-Wide Courses
}

Kevin Craig

Marquette University

Mark L. Nagurka

Marquette University, mark.nagurka@marquette.edu

Accepted version. Published as a part of 2010 IEEE Transforming Engineering Education: Creating Interdisciplinary Skills for Complex Global Environments, April 6-9, 2010. DOI. C 2019 IEEE. Used with permission. 


\title{
Marquette University
}

\section{e-Publications@Marquette}

\section{Mechanical Engineering Faculty Research and Publications/College of Arts and Sciences}

This paper is NOT THE PUBLISHED VERSION; but the author's final, peer-reviewed manuscript. The published version may be accessed by following the link in the citation below.

2010 IEEE Trasforming Engineering Education : Creating Interdisciplinary Skills for Complex Global Environments, (April 2010). DOI. This article is (C) IEEE and permission has been granted for this version to appear in e-Publications@Marquette. IEEE does not grant permission for this article to be further copied/distributed or hosted elsewhere without the express permission from IEEE.

\section{Multidisciplinary Engineering Systems 2nd and 3rd Year College-Wide Courses}

\author{
Kevin Craig \\ College of Engineering, Marquette University, Milwaukee, WI, USA \\ Mark Nagurka \\ College of Engineering, Marquette University, Milwaukee, WI, USA
}

\begin{abstract}
Undergraduate engineering education today is ineffective in preparing students for multidisciplinary system integration and optimization - exactly what is needed by companies to become innovative and gain a competitive advantage in this global economy. While there is some movement in engineering education to change that, this change is not easy, as it involves a cultural change from the silo approach to a holistic approach. The ABET-required senior capstone multidisciplinary design course too often becomes a design-buildtest exercise with the emphasis on just getting something done. Students rarely break out of their disciplinary comfort zone and thus fail to experience true multidisciplinary system design. What is needed are multidisciplinary systems courses, with a balance between theory and practice, between academic rigor and the best practices of industry, presented in an integrated way in the 2 nd and $3 r d$ years that prepares students for true multidisciplinary systems engineering at the senior level and beyond. The two courses presented here represent a significant curriculum improvement in response to this urgent need.
\end{abstract}




\section{SECTION I. Current Situation}

It is widely recognized that the future of the U.S. and indeed our everyday lives are increasingly dependent on scientific and technical innovation. However, the United States is in an innovation crisis fueled by a crisis in engineering education. The innovation shortfall of the past decade is real and there have been far too few commercial innovations that can transform lives and solve urgent human problems. Society's problems are getting harder, broader, and deeper and are multidisciplinary in nature. They require a multidisciplinary systems approach to solve them and present-day engineering education is not adequately preparing young engineers for the challenge. Basic engineering skills have become commodities worldwide. To be competitive, U.S. engineers must provide high value by being immediate, innovative, integrative, conceptual, and multidisciplinary. In addition, innovation is local - you don't import it and you don't export it! You create it! It is a way of thinking, communicating, and doing.

Innovation, the process of inventing something new, desirable, useful, and sustainable, happens at the intersection of technology, business, human factors, and complexity (Figure 1).



Fig. 1. How Innovation Happens

In addition to addressing the nation's needs for economic growth and defense, engineers, scientists, and mathematicians must identify and solve societal problems that benefit people, their health and quality of life, and the environment. The STEM (science, technology, engineering, and mathematics) disciplines must embrace a renewed human-centered focus and along with that a face that attracts a diversity of students interested in serving people at home and worldwide. Ninety percent of the engineering in the world today addresses the needs of the richest ten percent of the population. What about the other $90 \%$ ? STEM students, as well as students from the humanities, arts, social sciences, and business, must all realize they are partners in solving the innovation crisis. They each play a vital role and must be able to identify the needs of people, to critically think and solve problems, to generate human-centered ideas and rapidly prototype concepts, to integrate human values and business into concepts, to manage complexity, to work in multidisciplinary teams, and to effectively communicate results. The quality of STEM education in innovation, both in K-12 and at universities, has a direct impact on our ability as a nation to compete in the increasingly competitive global arena. 




Fig. 2. Real-World Problem Solving

Engineering, science, and mathematics educators face daunting challenges to prepare this next wave of STEM professionals. In general, the current preparation of students is inadequate for the challenge. Students focus on facts, tests, and grades and fail to understand concepts and processes. They are unable to integrate knowledge, processes, techniques, and tools, both hardware and software, to solve a multidisciplinary problem. Students need first, and foremost, to become critical-thinking problem solvers. Indeed, one of the great failures in STEM education has been the inability of graduating students to integrate all they have learned in the solution of a real-world problem, as the cartoon (Figure 2) suggests.

Students need to be shown the difference between studying engineering and becoming an engineer. They need to experience in a hands-on, minds-on way what it is to be an engineer-and this must happen early and often during their four-year academic career. The exclusive use of straight lecturing and the posing of questions for which there is only one correct answer must be replaced by discovery learning and learning with understanding. Faculty must guide students to discover engineering through the process of active investigation which: nurtures curiosity, initiative, and risk taking; promotes critical thinking; develops students' responsibility for their own learning and habits of life-long learning; and fosters intellectual development and maturity. 


\section{SECTION II. College of Engineering Response}

A $21^{\text {st }}$-century vision for a College of Engineering is shown in Figure 3. The college must be more than just the sum of the engineering departments, each operating in its own silo. A $21^{\text {st }}$-century College of Engineering must respond to these urgent needs in three ways:

- $\quad \underline{K}-12$ Outreach that includes not only STEM disciplines but all students, e.g., humanities, social sciences, arts, business, as all will play key roles in addressing the innovation crisis. This outreach must be fully integrated into the College of Engineering, as it is foundational. All engineering departments must be fully involved and informed.

- $\quad$ Transformation of students, faculty, curricula, administrators, and facilities within the College of Engineering based on a Discovery Learning philosophy and a multidisciplinary systems approach to problem solving.

0 Discovery Learning is at the core of a College of Engineering and is best defined by the student commitments or outcomes it brings about than the teaching methods used: critical thinking, independent inquiry, responsibility for one's own learning, and intellectual growth and development. There are a range of strategies used to promote learning, e.g., interactive lecture, discussion, problem-based learning, case studies, but no exclusive use of traditional lecturing! Instructors assist students in mastering and learning through the process of active investigation. It is student-centered with a focus on student development.

- Renewed emphasis on genuine University - Industry Interaction to create a culture of innovation both throughout the College of Engineering and within industry partner companies. This interaction must be one of mutual collaboration, as only through a balance of theory and practice, i.e., academic rigor and best industrial practices, can the challenging multidisciplinary problems be solved.

\section{College of Engineering}

More Than Just Outstanding Engineering Departments

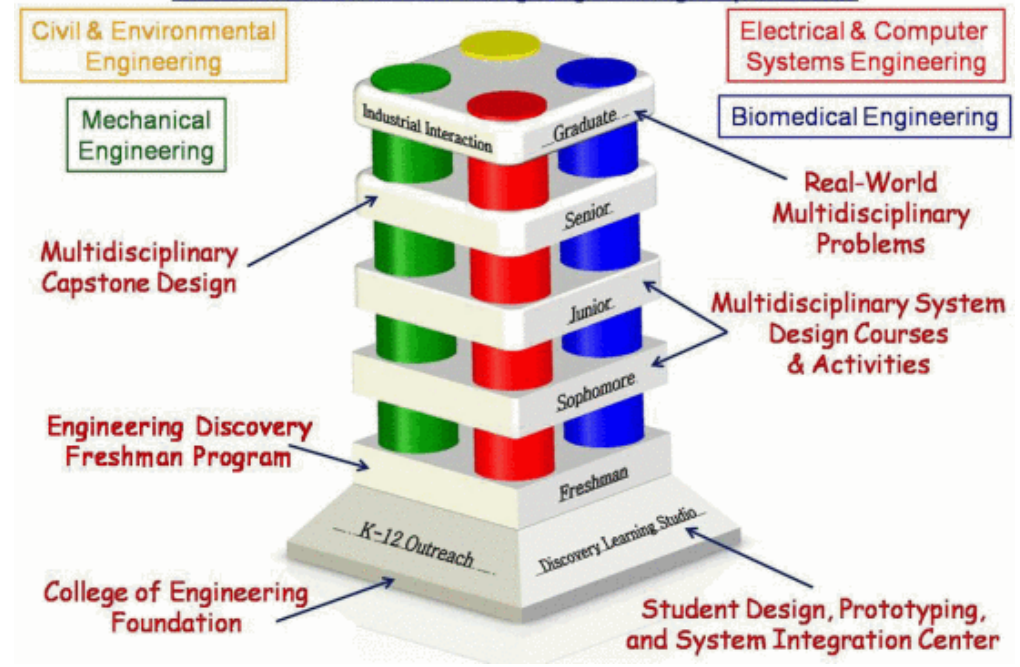

Fig. 3. College of Engineering Response

What is the best way to train a student to become a practicing engineer? As shown in Figure 4, only through industrial interaction - knowing the types of problems engineers face, the concepts, processes, and tools they use to solve those problems, and the personal and professional attributes essential to be an engineer leadernot a follower - but an independent-thinking leader in our technological society - can we develop engineering curricula to transform our students. 
Modern engineering systems are multidisciplinary (Figure 5) requiring, from the start of the design process, integration and simultaneous optimization of the physical system, sensors, actuators, electronics, computers, and controls. This requires a new type of engineer, one with disciplinary depth and multidisciplinary breadth and a balance between theory and practice (Figure 6).



Fig. 4. Innovation and Integration

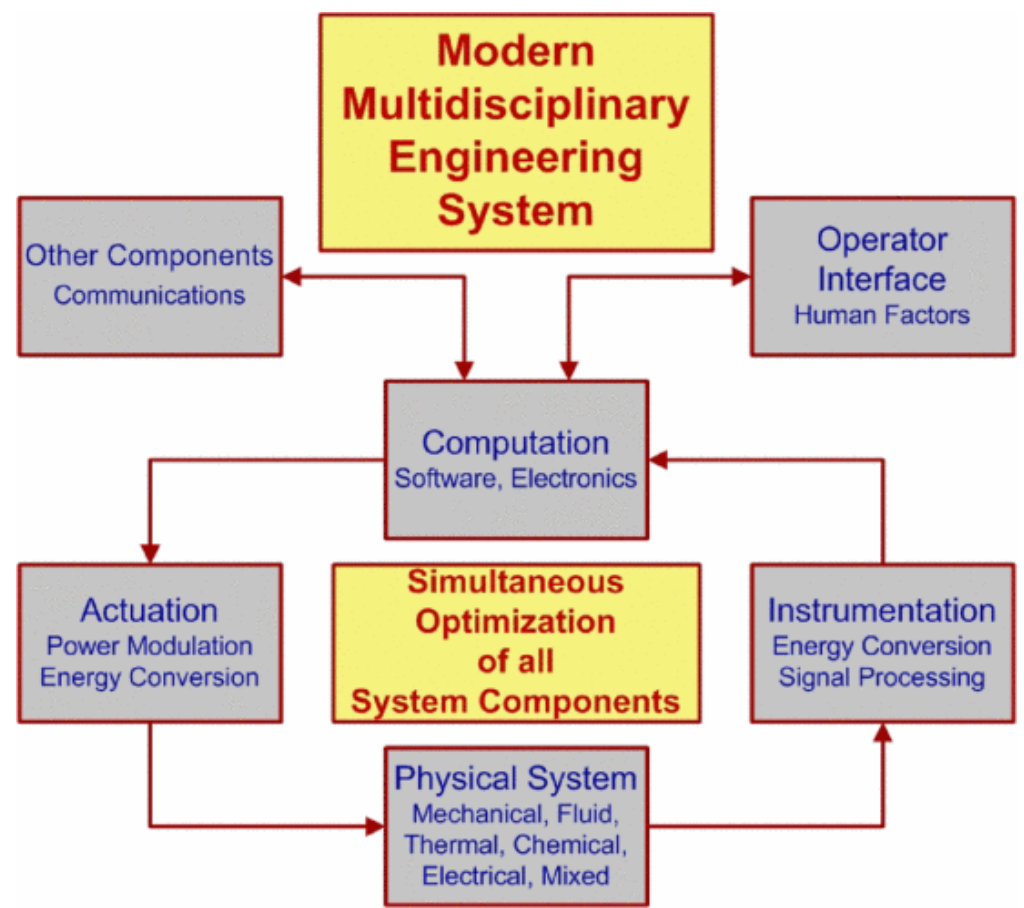

Fig. 5. Modern Multidisciplinary Engineering System 


\section{Engineering Breadth}
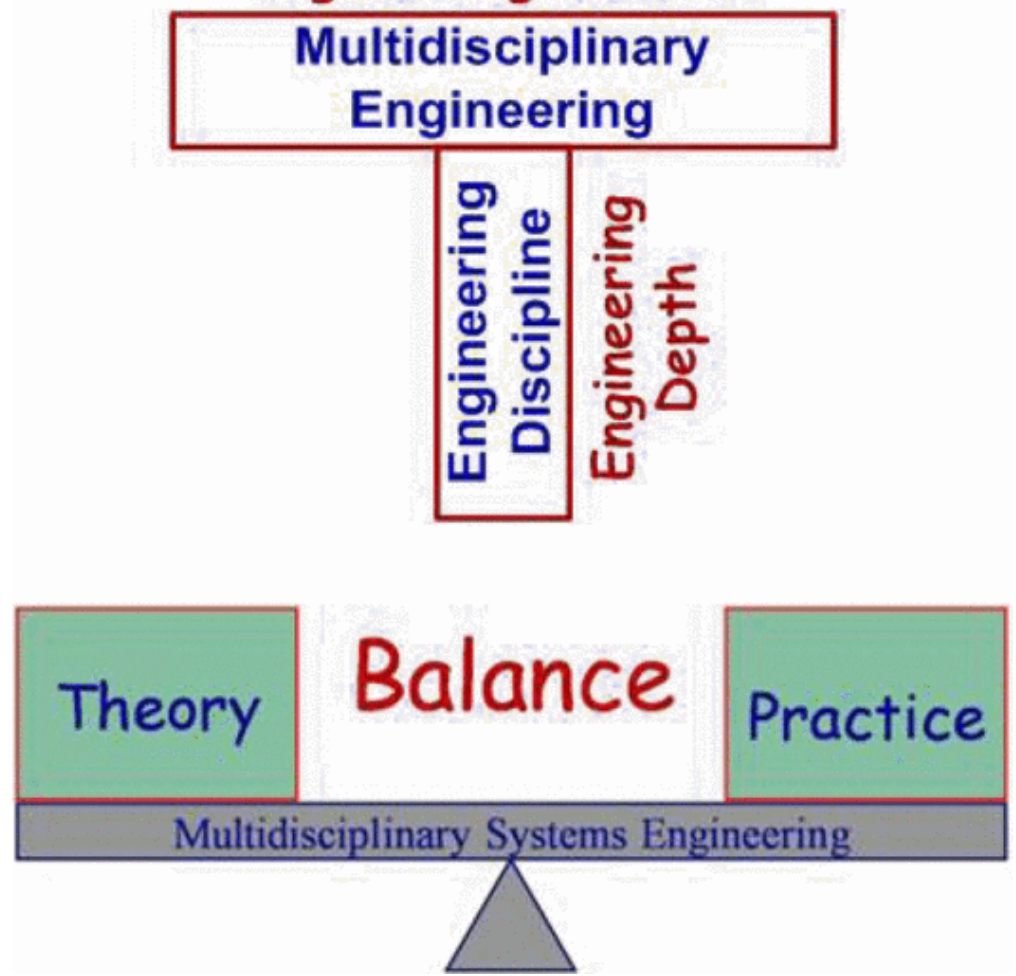

Fig. 6. Modern Multidisciplinary Systems Engineer

\section{SECTION III. Multidisciplinary Engineering Systems Courses}

The solution to real-world problems requires a multidisciplinary engineering systems approach that must start with the freshman engineering program and continue through the second and third years with multidisciplinary engineering college-wide experiences leading to the senior capstone design course.

The senior ABET-required multidisciplinary engineering capstone design course very often has serious deficiencies.

- Too often this course becomes a design-build-test exercise with the emphasis on just getting something done. Students rarely break out of their disciplinary comfort zone and thus fail to experience true multidisciplinary system design.

- In evaluating concepts, a modeling-and-analysis approach must replace any design-build-and-test approach, but this modeling is multidisciplinary and crosses domain boundaries. This rarely happens in this course.

- Multidisciplinary teams must apply human-centered, model-based design techniques.

- The course focus must be on multidisciplinary system design and integration, working outside one's comfort zone, learning new skills, concepts, tools (hardware and software), and not being afraid to fail.

- This course should not be all about deliverables (i.e., getting something built, getting a report submitted), but should reflect how multidisciplinary teams work in modern engineering practice, i.e., each team member with depth in a technical area but also breadth across many areas so as to be active participants in the total system design.

- $\quad$ Figure 7 shows a typical modern multidisciplinary engineering system design team. The capstone design course should prepare graduating engineers for this reality.

To facilitate the transformation of the senior capstone design course and better prepare students for professional engineering practice, two multidisciplinary engineering systems courses have been developed for 
the entire College of Engineering to fill the multidisciplinary system engineering void in the $2^{\text {nd }}$ and $3^{\text {rd }}$ years. The details are shown in Figure 8; course descriptions follow.

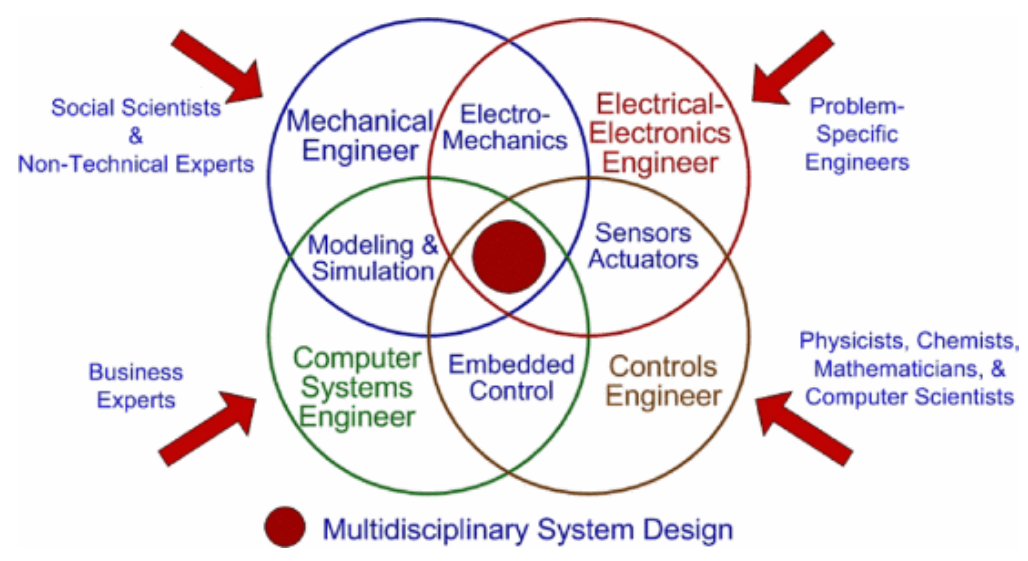

Fig. 7. Multidisciplinary Engineering System Design Team

\section{Engineering Systems $1 \& 2$}



Fig. 8. $2^{\text {nd }}$ and $3^{\text {rd }}$ Year Engineering Systems Courses

- Engineering Systems 1

Electromechanical engineering systems and the Engineering System Investigation Process. Physical and mathematical modeling of mechanical, electrical, magnetic, and electromechanical systems. Dynamic analysis: time response and frequency response; analytical and numerical simulation. Electromechanical 
actuators: solenoid, vibration exciter, and brushed de motor. Introduction to measurement systems: analog and digital; motion, electrical, and magnetic sensors. Electronics for actuators, sensors, and controls. Introduction to control systems: analog vs. digital, open-loop vs. closed-loop, stability, and performance. Introduction to On-Off and PID control. Industrial case studies emphasizing integration. Laboratory exercises throughout the course. Extensive use of MatLab and LabVIEW. $2^{\text {nd }}$ Year, 3 credits: two 50-minute classes, two 110-minute studios.

- Engineering Systems 2

Multidisciplinary engineering systems and the Engineering System Investigation Process. Physical and mathematical modeling of thermal, fluid, and multidisciplinary systems. Dynamic analysis: time response and frequency response; analytical and numerical simulation. Electromechanical actuators: brushless de motors and step motors. Fluid actuators: hydraulic and pneumatic. Measurement systems: analog and digital; thermal and fluid sensors. Electronics for actuators, sensors, and controls. Control system design: root-locus and frequency-response methods, PID control, state-space control, industrial control. Industrial case studies emphasizing integration. Laboratory exercises throughout the course. Extensive use of MatLab and LabVIEW. $3^{\text {rd }}$ Year, 3 credits: two 50-minute classes, two 110-minute studios.

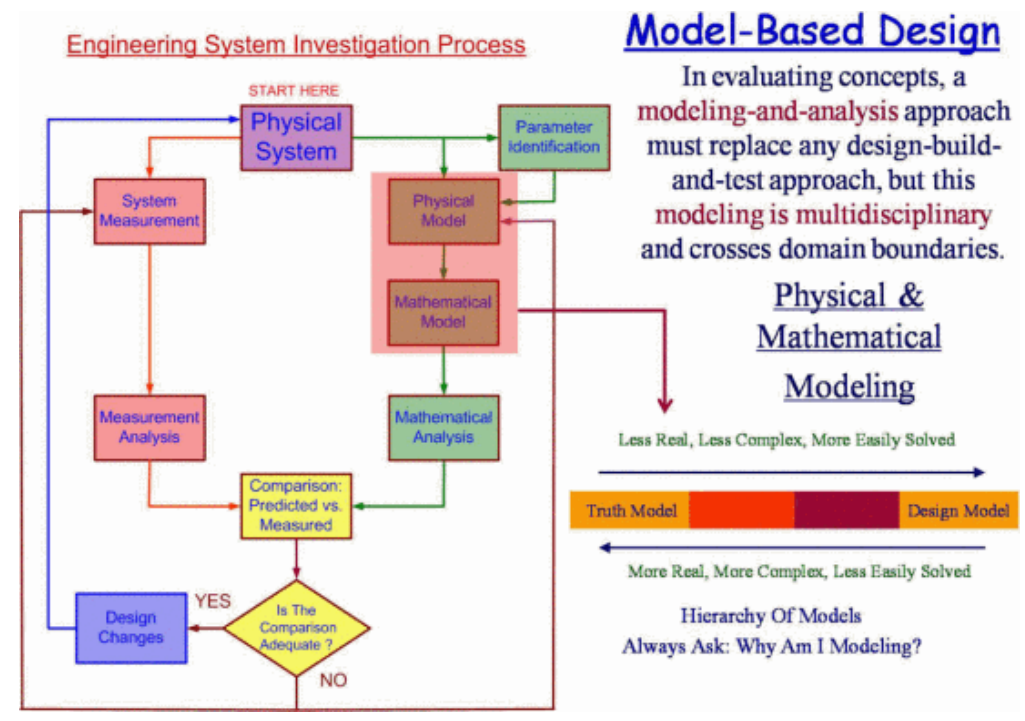

Fig. 9. Model-Based Design

The emphasis in these courses is on innovation and integration through model-based design (Figure 9). In most department curricula, courses are taught as stand-alone courses often with little real-world context and little or no integration with other courses, e.g., separate courses in modeling and analysis, electric circuits / electronics, electromechanics, sensors and measurement systems, controls, digital signal processing, fluid power, etc. These must be taught in an integrated way and in the context of a modern multidisciplinary engineering system (see Figure 5).

These two courses address these deficiencies. They are initially being taught as part of the mechanical engineering curriculum (diagram right), but can easily be adapted to any discipline through discipline-specific application modules, as the fundamentals in each of these subject areas is the same for all disciplines and application areas. These courses are presently being developed and will be first taught in the spring 2011 semester. 




\section{Summary}

Undergraduate engineering education today is ineffective in preparing students for multidisciplinary system integration and optimization - exactly what is needed by companies to become innovative and gain a competitive advantage in this global economy. While there is some movement in engineering education to change that, this change is not easy, as it involves a cultural change from the silo approach to a holistic approach. The ABET-required senior capstone multidisciplinary design course too often becomes a design-buildtest exercise with the emphasis on just getting something done. Students rarely break out of their disciplinary comfort zone and thus fail to experience true multidisciplinary system design. What is needed are multidisciplinary systems courses, with a balance between theory and practice, between academic rigor and the best practices of industry, presented in an integrated way in the $2^{\text {nd }}$ and $3^{\text {rd }}$ years that prepares students for true multidisciplinary systems engineering at the senior level and beyond. The two courses presented here represent a significant curriculum improvement in response to this urgent need.

\section{Keywords}

\section{IEEE Keywords}

Systems engineering and theory, Educational institutions, Technological innovation, Engineering education , Cultural differences, Business , Art, Best practices, Human factors, Environmental economics

\section{INSPEC: Controlled Indexing}

educational courses, engineering education 
INSPEC: Non-Controlled Indexing

multidisciplinary engineering systems, undergraduate engineering education, design-build-test exercise , curriculum improvement, college-wide courses 